\title{
EDITORIAL
}

\section{REVISTA ESPAÑOLA DE SALUD PÚBLICA - MEMORIA DE ACTIVIDADES 2019}

Ma Aranzazu López Franco (1), Pello Latasa Zamalloa (2), Laura Molinera Gómez (3) y Rubén Martín Bravo (4)

(1) Revista Española de Salud Pública. Ministerio de Sanidad. Madrid. España.

(2) Centro de Alertas y Emergencias Sanitarias. Ministerio de Sanidad. Madrid. España.

(3) Apoyo administrativo TRAGSATEC. Subdirección General de Promoción de la Salud y Vigilancia en Salud Pública. Madrid. España.

(4) Técnico de Diseño Externo TRAGSATEC. Revista Española de Salud Pública. Ministerio de Sanidad. Madrid. España.

Presentamos la memoria anual de actividades de la Revista Española de Salud Pública (RESP) con el fin de evaluar los logros alcanzados durante este año y las novedades más relevantes puestas en marcha. Nuestro principal objetivo es establecer nuevas líneas de mejora de cara a los próximos años. Queremos destacar la presencia de la RESP en Twitter a partir del último trimestre y el establecimiento de alianzas profesionales, como la formada con Gaceta Sanitaria, que nace de la necesidad de construir sinergias entre las revistas de Salud Pública, reivindicar el papel de los comités de las mismas, y buscar estrategias mutuas que nos permitan hacer más relevante el papel actual de las publicaciones científicas de calidad.

Cifras: Los manuscritos remitidos a nuestra revista durante 2019 fueron 322 (328 en 2018), y se rechazaron 166 sin pasar a revisión externa, lo que equivale a una tasa de rechazo inicial del 51,55\% (durante el año anterior fue del 51,83\%). Los motivos más frecuentes de rechazo fueron que el manuscrito no era adecuado para publicarlo en la RESP (bien por su falta de calidad en los datos o porque el tema no encajaba con el ámbito de la revista), o porque los datos a publicar sólo tenían interés a nivel local y carecía de validez externa. Este último motivo, fue muy frecuente entre los manuscritos remitidos desde América Latina. Durante 2019 recibimos un total de 80 artículos desde Latinoamérica (89 en 2018), de los cuales se publicaron solamente 2 (1 en 2018) debido a los motivos ya mencionados.

El tiempo entre la aceptación del artículo por parte del revisor externo y la publicación se mantiene en torno a las 8-10 semanas, siendo una de las líneas de mejora a trabajar. Respecto al año anterior, hemos reducido a la mitad el tiempo que transcurre entre la entrada del artículo y la aceptación o rechazo del mismo, pero los tiempos de revisión siguen siendo muy altos (figura 1).

Hemos observado que se mantiene la tendencia de los últimos años en cuanto al origen de los manuscritos recibidos por comunidad autónoma (figura 2), y las regiones que más envían son Madrid, Andalucía, Cataluña y Comunidad Valenciana. Se observó en 2019 un incremento en los manuscritos remitidos desde Asturias.

En cuanto a los artículos publicados por tipo de artículo, se publicaron más editoriales (6) que el año anterior, el número de revisiones bibliográficas sigue siendo bajo y aumentó el número de originales publicados (figura 3 ).

Además se publicaron 3 números monográficos: uno sobre vacunación, otro sobre tabaco y otro sobre VIH (virus de inmunodeficiencia 


\section{Figura 1}

Tiempo entre la entrada del artículo y la aceptación o rechazo del mismo.

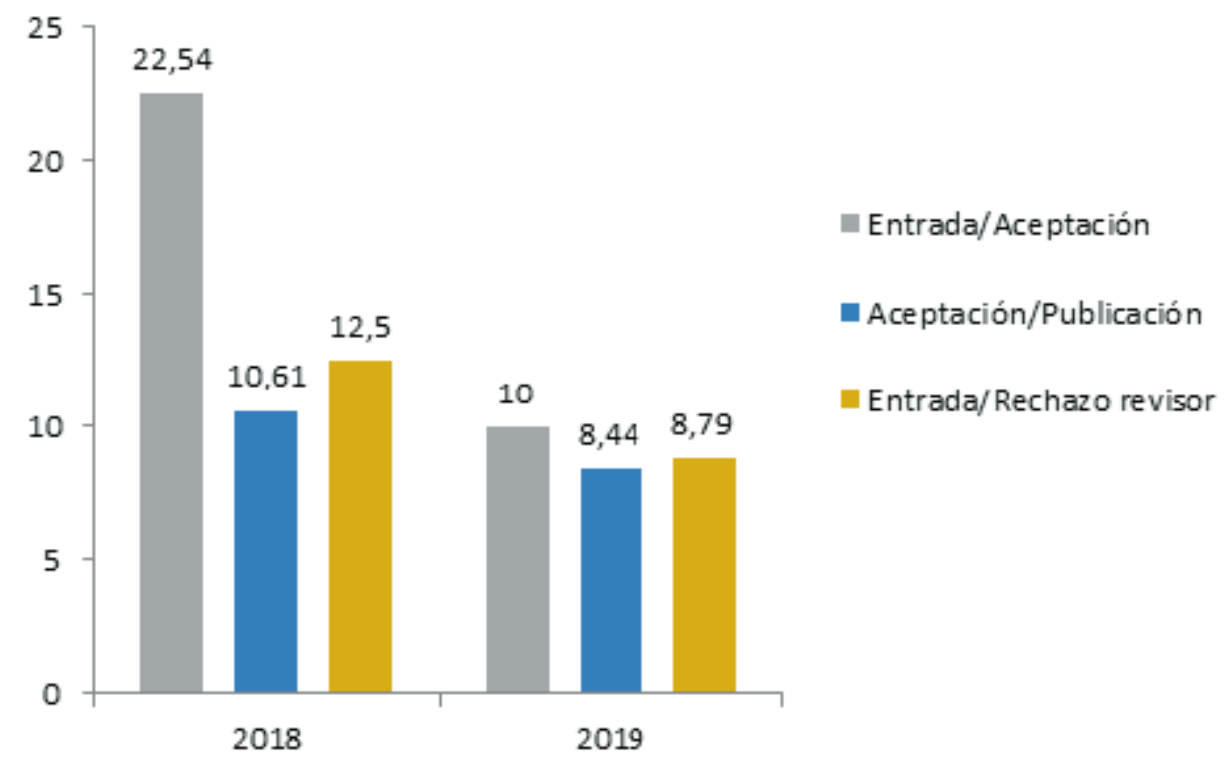

Figura 2

Artículos recibidos por comunidad autónoma en 2019.

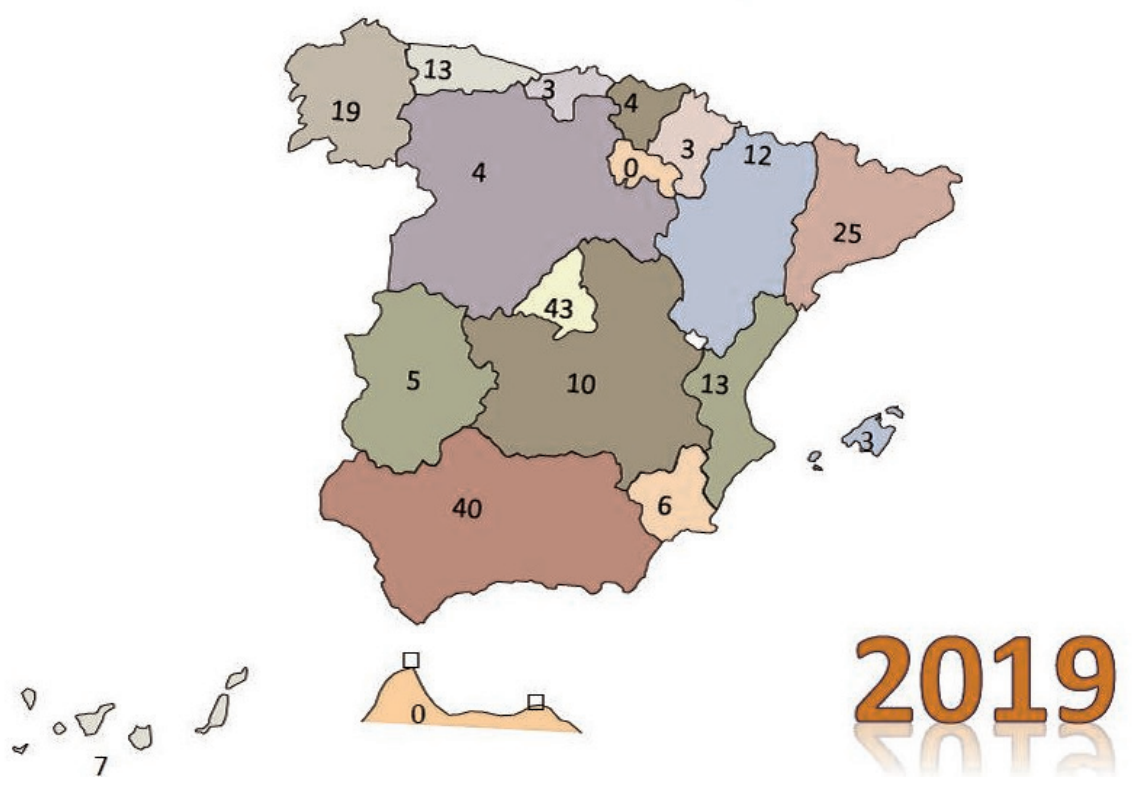


Figura 3

Artículos recibidos por tipo en 2019.

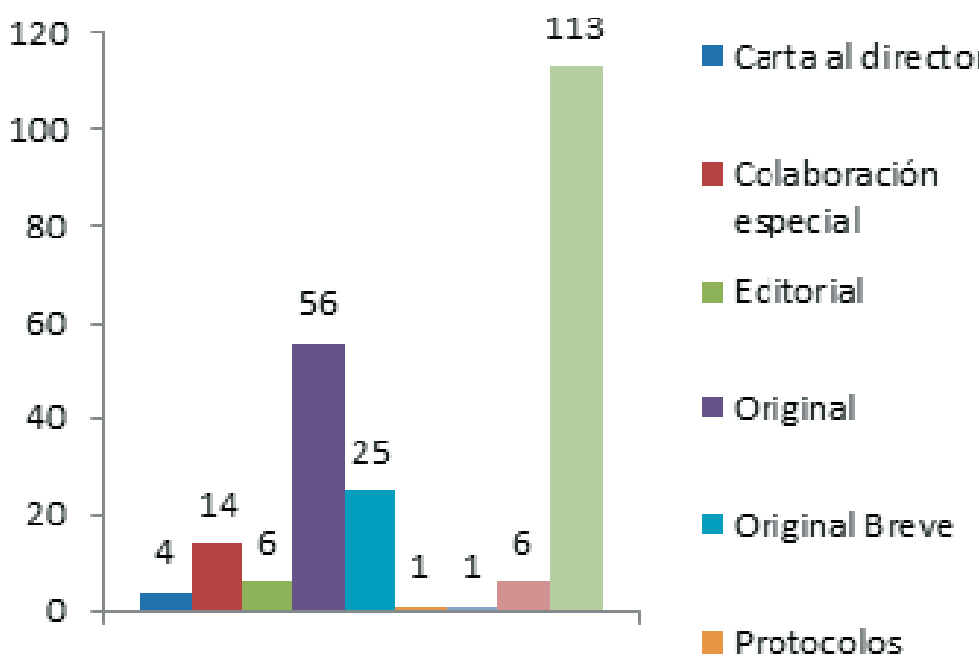

humana) y otras ITS (infecciones de transmisión sexual). Estos monográficos han sido editados en papel y pueden solicitarse al ministro de Sanidad por parte de instituciones o asociaciones científicas a través del correo electrónico de la revista: resp@mscbs.es.

Las áreas temáticas sobre las que se publicó fueron muy diversas, destacando, además de las de los citados monográficos, las de servicios sanitarios, salud materno infantil, salud cardiovascular, salud mental, alimentación y nutrición, y salud laboral.

El factor de impacto: Nuestro factor de impacto JCR (Journal Citation Index), calculado por Clarivate Analytics, para el año 2018 fue de 0,635, igual que el del año 2017, si bien el número de artículos publicados durante 2018 fue mayor (figura 4). Esperamos que las últimas mejoras en el proceso de publicación en estos últimos dos años repercutan en el índice de impacto de 2019, ya que el de 2018 tuvo en cuenta las citas realizadas durante 2016 y 2017. Por otro lado, la RESP es firmante de la Declaración de Sant
Joan d'Alacant y de la Declaración DORA, asumiendo el compromiso de reducir el énfasis del índice de impacto y de otras métricas basadas en indicadores sobre la revista, así como promover nuevos indicadores relacionados con el contenido científico del artículo.

Desarrollo e innovación en la RESP: Durante 2019 hemos asumido nuevos retos como iniciar la presencia en redes sociales, concretamente en la red social Twitter, en la que ya contamos con casi 2.000 seguidores y hemos publicado 134 tuit en sólo 5 meses. Además hemos abierto una sección de Suplementos, que acoge los monográficos publicados durante el año (en 2019, sobre tabaco, vacunas, y VIH y otras ITS) y donde también se pueden consultar los programas de las jornadas realizadas en el Ministerio de Sanidad relacionadas con la Salud Pública, algunas de las cuales cuentan con resúmenes de las ponencias. A finales de año se creó un nuevo tipo de trabajo denominado "Protocolos", que recoge artículos en los que se explica la metodología de estudios o ensayos. Además, este año (febrero de 2020) 


\section{Figura 4}

Número de artículos publicados y factor de impacto. 2014-2018.

\section{-Artículos - FI}

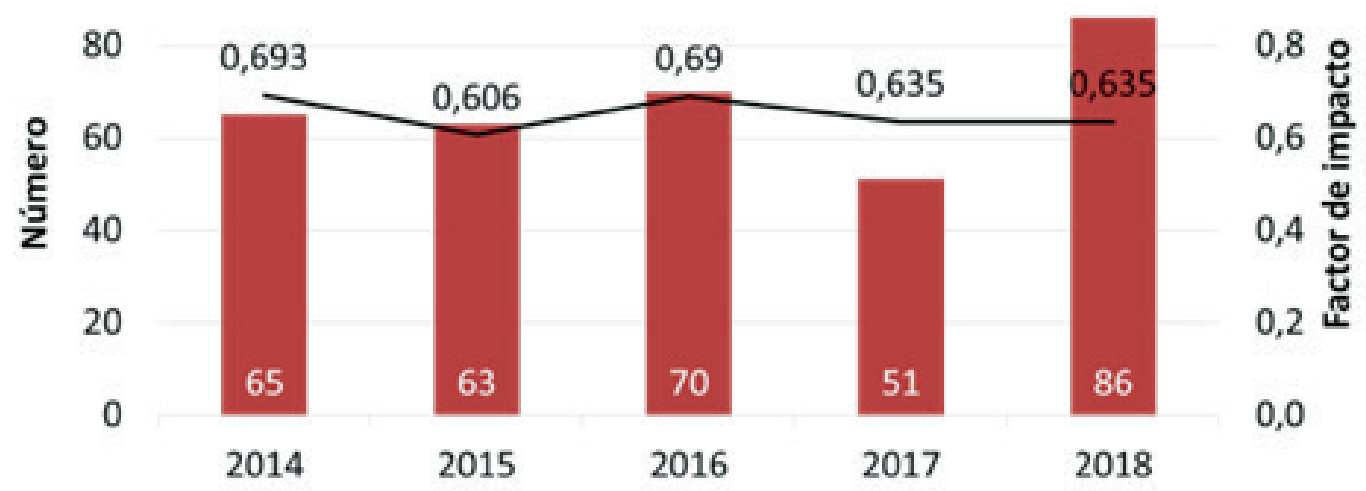

hemos abierto una sección de "Historia de la Salud Pública" donde recogeremos todos aquellos trabajos que realizaron una revisión histórica de temas relacionados con la Salud Pública. Algunas de estas innovaciones surgen a propuesta del Comité Científico de la RESP. Dicho Comité ha sufrido una importante reestructuración y se han aprobado unas nuevas normas de funcionamiento para el mismo, con el objetivo de cumplir nuestro compromiso de mantener la calidad de la revista.

Para este 2020 la revista se enfrenta a importantes retos como son la modernización de su web, aumentar el número de artículos traducidos al inglés y actualizar las normas de publicación de la RESP. La continua mejora del proceso de maquetación, la gestión más eficiente y práctica de nuestras bases de datos y del sistema de consulta de cara al usuario, así como el enriquecimiento constante y la visibilidad de nuestro archivo de números pasados (actualmente disponibles hasta 1981), serán otros objetivos de nuestro trabajo diario. Además, junto con Gaceta Sanitaria, queremos facilitar a los profesionales que trabajan en el campo de la Salud Pública la publicación de artículos en ambas revistas, por lo que pondremos en marcha cursos de formación sobre el proceso de publicación de artículos científicos.

Finalmente, queremos agradecer a los numerosos revisores que colaboran desinteresadamente con esta revista, a la Dirección General de Salud Pública, Calidad e Innovación del Ministerio de Sanidad por su apoyo incondicional para la introducción de mejoras e innovaciones en el proceso editorial, así como a la Subdirección General de Tecnologías de la Información y a la Subdirección General de Atención al Ciudadano, sin cuya ayuda no hubiésemos podido llevar a cabo todas estas mejoras. Y, en particular, desear a Pello Latasa Zamalloa, que ha sido un miembro indispensable en el equipo de redacción de la RESP, mucha suerte en su nueva andadura como Experto Nacional en la Comisión Europea. 